Article

\title{
Fabrication of an All-Solid-State Carbonate Ion-Selective Electrode with Carbon Film as Transducer and Its Preliminary Application in Deep-Sea Hydrothermal Field Exploration
}

\author{
Chuqing Zhang ${ }^{1,2,3} \mathbb{1}$, Yang He ${ }^{1,2,3}$, Jianbo Wu ${ }^{1}$, Manqing Ai ${ }^{1,2,3}$, Wei Cai ${ }^{4}$, Ying Ye ${ }^{1}$, Chunhui Tao ${ }^{2,3, *}$, \\ Pingping Zhang ${ }^{1}$ and Quan Jin ${ }^{1}$ \\ 1 Ocean College, Zhejiang University, Zhoushan 316021, China; 21934074@zju.edu.cn (C.Z.); \\ 22034103@zju.edu.cn (Y.H.); oswien@zju.edu.cn (J.W.); aimanqing@yeah.net (M.A.); \\ gsyeying@zju.edu.cn (Y.Y.); marin011@163.com (P.Z.); jinquanto@163.com (Q.J.) \\ 2 Key Laboratory of Submarine Geosciences, Ministry of Natural Resources, Hangzhou 310012, China \\ 3 Second Institute of Oceanography, Ministry of Natural Resources, Hangzhou 310012, China \\ 4 Department of Ocean Science and Engineering, Southern University of Science and Technology, \\ Shenzhen 518055, China; caiw@sustech.edu.cn \\ * Correspondence: taochunhuimail@163.com
}

Citation: Zhang, C.; He, Y.; Wu, J.; Ai, M.; Cai, W.; Ye, Y.; Tao, C.; Zhang, P.; Jin, Q. Fabrication of an All-Solid-State Carbonate Ion-Selective Electrode with Carbon Film as Transducer and Its Preliminary Application in Deep-Sea Hydrothermal Field Exploration. Chemosensors 2021, 9, 236. https:// doi.org/10.3390/chemosensors9080236

Academic Editors: Luís C. Coelho and José Manuel M. M. de Almeida

Received: 27 July 2021

Accepted: 13 August 2021

Published: 23 August 2021

Publisher's Note: MDPI stays neutral with regard to jurisdictional claims in published maps and institutional affiliations.

Copyright: (c) 2021 by the authors. Licensee MDPI, Basel, Switzerland. This article is an open access article distributed under the terms and conditions of the Creative Commons Attribution (CC BY) license (https:/ / creativecommons.org/licenses/by/ $4.0 /)$.

\begin{abstract}
Real-time measurements of carbonate ion concentrations in the ocean are critical to advancing marine environmental monitoring and research into deep-sea hydrothermal activity. Herein, we report the first example of deep-sea hydrothermal field exploration using a carbonate ion-selective electrode (ISE). The novel carbonate ISE was composed of a Ni wire as substrate, carbon film as transducers and carbonate-selective membrane layers. This paper describes the preparation process of the electrode and characterises its performance via scanning electron microscopy (SEM) and electrochemical analysis. The detection limit of the electrode for $\mathrm{CO}_{3}{ }^{2-}$ is $2.821 \times 10^{-6} \mathrm{~mol} / \mathrm{L}$, the linear response range is $1.0 \times 10^{-5}-1.0 \times 10^{-1} \mathrm{~mol} / \mathrm{L}$ and the Nernst slope was $-30.4 \mathrm{mV} / \mathrm{decade}$. In April 2021, the carbonate ISE was mounted on multi-parameter sensors with $\mathrm{pH}$ and Eh (redox) electrodes for the search of hydrothermal activity at the Southwest Indian Ridge. The simultaneous potential anomalies appeared at this carbonate electrode with the $\mathrm{pH}$ and Eh electrodes when passing through the hydrothermal field. The study of the hydrothermal field was supported by the in situ camera video and the sulphide samples. Additionally, the carbonate electrode provides enhanced information of water chemistry for the study of the hydrothermal field.
\end{abstract}

Keywords: ion-selective electrode; carbonate determination; carbon film; hydrothermal field

\section{Introduction}

Carbon dioxide is one of the important greenhouse gases in the atmosphere, with around $28 \%$ of atmospheric $\mathrm{CO}_{2}$ being dissolved in seawater [1]. In recent years, as atmospheric carbon dioxide levels have increased, the production of excess carbonate ions has led to the frequent acidification of seawater, and had a significant impact on marine ecosystems [2-4]. In addition, hydrothermal-associated $\mathrm{CO}_{3}{ }^{2-}$ enrichment is a hallmark feature of hydrothermal fluid, where dissolved $\mathrm{CO}_{2}$ concentrations may be tens of times higher than in seawater, with significant implications for the global carbon cycle and climate change [5-7]. Therefore, accurate knowledge of carbonate levels in seawater is necessary to maintain the balance of marine ecosystems, while the implementation of realtime monitoring of carbonate ion concentrations in hydrothermal fluids is a major advance in the detection of hydrothermal fields [2,3,8-10]. Most of the commonly used methods for determining carbonate concentrations rely on laboratory analytical instruments such as gravimetric methods, colour change, equilibrium pressure, gas chromatography, infrared spectrophotometry and coulometric titration [11-17]. These analytical methods require sample pre-treatment, which is a complex, time-consuming and insensitive process, cannot 
meet the demands of long-term field monitoring. In contrast, all-solid-state ion-selective electrodes are of increasing interest due to their ease of manufacture, cost effectiveness, portability and high sensitivity [18].

Various researchers have made attempts to fabricate carbonate electrodes. Zhao et al. fabricated an all-solid carbonate electrode by using $\mathrm{Ag}_{2} \mathrm{CO}_{3}-\mathrm{BaCO}_{3}$ as a sensitive layer and applied it to heat exchange water analysis [19]. Mendecki et al. altered the sensor's conditioning protocol to fabricate a carbonate sensor with an extremely low detection limit [20]. Mei et al. described the polymeric membrane ion-selective electrodes for determination of carbonate [21], while Li et al. developed a novel disposable all-solidstate carbonate-selective electrode based on a screen-printed carbon paste electrode [22] Nevertheless, most of the electrodes prepared by these methods have a narrow linear range, are inherently expensive and are non-resistant to impurity ions in seawater. To our knowledge, no carbonate electrodes have been reported for application in long-term deep-sea environmental monitoring and deep-sea hydrothermal activity studies.

Herein we report the development of a novel all-solid-state carbonate ion-selective electrode (ISE) by using a $\mathrm{Ni}$ wire as the substrate, carbon film as the interlayer and polymeric membrane as sensitive layer. The ISE had a linear range of $10^{-5} \mathrm{M}$ to $10^{-1} \mathrm{M}$, a response time of less than $1 \mathrm{~s}$, were resistant to seawater interference and can be used in marine environments. The manufacturing process of the ISE is simple; the completed product was $0.5 \mathrm{~mm}$ in diameter and $6-12 \mathrm{~mm}$ in length and can be easily integrated into the same sensor device with other electrodes to monitor multiple ions simultaneously. The prepared electrodes enable real-time measurement of carbonate ion concentrations in hydrothermal fluid and long-term monitoring of carbonate ion concentrations in the ocean.

\section{Materials and Methods}

The process of preparing an all-solid carbonate electrode is briefly described as follows. Firstly, a carbon film is plated on the surface of the nickel wire by electrochemical methods, then a carbonate-sensitive film is applied to the surface of the carbon plated nickel wire using the dipping method. The schematic diagram is shown in Figure 1.

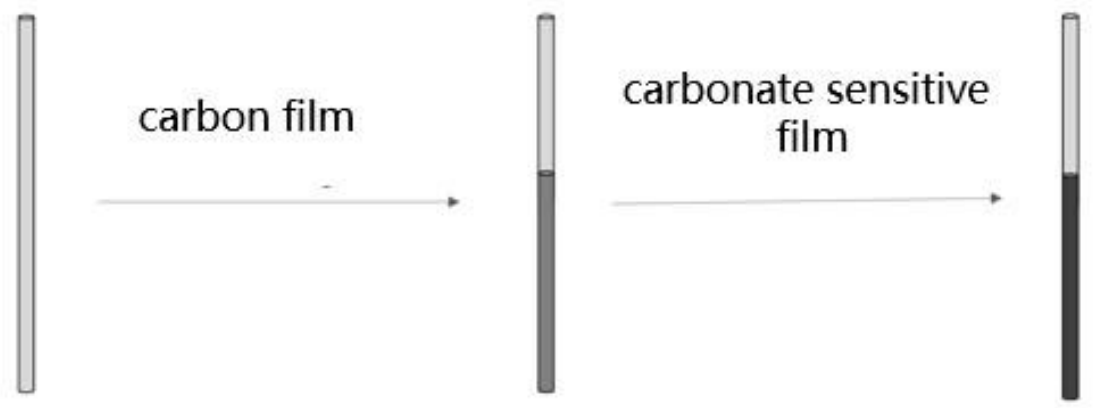

Figure 1. Diagram of the electrode preparation process.

\subsection{Reagents and Apparatus}

A Ni wire (99.9\%, $0.5 \mathrm{~mm}$ in diameter) was obtained from the Precious Materials Company of Changzhou, China. Carbonate ionophore VII (93206 Merck, Darmstadt, Germany) for the ISE were supplied by Merck. Dimethyl sulfoxide (DMSO), dibutyl phthalate, tetraoctyl ammonium chloride, ammonium thiocyanate, polyvinyl chloride (PVC) and imidazole were obtained from Aladdin (Shanghai, China). The sodium carbonate anhydrous, magnesium chloride, analytical-grade sodium chloride and hydrochloric acid were purchased from Sinopharm Chemical Reagent Co., Ltd (Shanghai, China). 


\subsection{Preparation of the Electrode}

\subsubsection{Carbon Film Coating}

The carbon film was prepared by cyclic voltammetry $(\mathrm{CV})$ method. The process is described below. The carbon film was coated on the Ni wire, using a three-electrode system by a CHI760D electrochemical workstation (Chenhua Company, Shanghai, China). The working electrode was a $\mathrm{Ni}$ wire, the reference electrode was a commercial $\mathrm{Ag} / \mathrm{AgCl}$ electrode and the auxiliary electrode was a Pt electrode. In a classic process, the plating was carried out in a self-prepared electrolyte solution, scanning 260 segments from 0 to $1.3 \mathrm{~V}$ at a rate of $100 \mathrm{mV} / \mathrm{s}$.

The electrolyte solution was synthesised as follows: $13.2 \mathrm{~g}$ imidazole $(0.09 \mathrm{~mol})$ was added into a $50 \mathrm{~mL}$ beaker with $4.29 \mathrm{~g}$ magnesium chloride anhydrous $(0.045 \mathrm{~mol})$, heated at 70 degrees until completely dissolved to solution $a$. Then, $13.71 \mathrm{~g}$ ammonium thiocyanate $(0.18 \mathrm{~mol})$ was added into $15 \mathrm{~g}$ dimethyl sulfoxide in a $50 \mathrm{~mL}$ beaker, stirred to dissolve to solution $b$. Next, the mixture of solution $a$ and solution $b$ was stirred and centrifuged, and its supernatant was used as the electrolyte solution for reserve.

During the preparation of the carbon film coating, the imidazole cations were aggregated towards the negative $\mathrm{Ni}$ wire in the presence of an applied electric field. Following this, they were catalytically degraded on the surface of the Ni to form monomeric carbon. This method enabled a metallurgical bond between the carbon coating and the metal substrate, showing a strong bonding capacity.

\subsubsection{Carbonate-Sensitive Film Coating}

The carbonate-sensitive film solution was made by dissolving a total of $100 \mathrm{mg}$ of carbonate ionophore VII (93206 Merck), dibutyl phthalate, tetraoctyl ammonium chloride, polyvinyl chloride ether in $1 \mathrm{~mL}$ of $\mathrm{N}, \mathrm{N}$-Dimethyl formamide (DMF), with a mass fraction of $5.2 \%, 47.1 \%, 0.6 \%$ and $92.4 \%$, respectively, as suggested by Merck, and stored at $2-8{ }^{\circ} \mathrm{C}$. The electrode, which had been covered with a carbon film coating, was immersed in the carbonate-sensitive film solution for $2 \mathrm{~s}$ at room temperature, then dried in a vacuum desiccator for $4 \mathrm{~h}$ at $35^{\circ} \mathrm{C}$.

DMF is highly volatile and small amounts of DMF on the electrode surface can evaporate rapidly, thus forming a polymeric carbonate-sensitive film on the electrode surface. The process did not require high temperatures for drying, avoiding different degrees of thermal expansion and contraction that can lead to flaking of the coating. The carbonate-sensitive film formed a surface with a certain curvature due to gravity during the evaporation of DMF. The structure of the membrane shortened the electrical signal transmission distance and reduced the electrode response time compared with flat shaped sensitive film.

After the course described above, the all-solid-state carbonate ion-selective electrode was carbon black and the gloss of the polymer film was visible, with a diameter of $0.5 \mathrm{~mm}$ and a length of 6-12 mm. The dense carbon film was approximately 500-600 nm thick and the carbonate-sensitive film was no more than $500 \mathrm{~nm}$ thick. They were coated in $\mathrm{Ni}$ filaments, and were close in length to the electrode.

\subsection{Evaluation of the Electrode}

SEM analysis was performed to analyse the microstructure involved in the carbon film for the electrode performance. The potentiometric properties of electrodes were evaluated at room temperature on the CHI760D electrochemical workstation. The electrode detection system is a two-electrode system with open circuit technology, with the prepared all-solid carbonate electrode as the indicator electrode and an $\mathrm{Ag} / \mathrm{AgCl}$ electrode as the external reference electrode. The dynamic response curves were obtained by measuring the potential in $\mathrm{Na}_{2} \mathrm{CO}_{3}$ solutions of different concentrations, while $1.0 \times 10^{-1}-10^{-8} \mathrm{M}$ $\mathrm{Na}_{2} \mathrm{CO}_{3}$ solutions were prepared by serial dilutions with deionized water. 


\section{Results and Discussion}

\subsection{SEM Analyses}

For the all-solid-state ion-selective electrodes, the electrical signals from the different solid layers tend to pass along each layer rather than across the interface, which is due to the interfacial impedance between the layers of the all-solid electrodes [23]. The carbon film coating on the surface of the nickel wire had good electrical conductivity and is tightly bonded to the polymer film, eliminating interfacial impedance with an effect similar to that of the internal electrolyte solution in conventional ion-selective electrodes [24-27].

Under scanning electron microscopy (SEM), Figure 2a presented a dense carbon film that was generated on the surface of the $\mathrm{Ni}$ wire by cyclic voltammetry. The physically broken surface of the carbon film was observed at high magnification (Figure $2 b$ ) and its composition remained comprised of carbon particles. The EDS analysis of the broken surface showed the element mass fraction of $76.58 \%$ for C, which was solid evidence for its composition. The SEM results proved that the prepared carbon film had a certain thickness and completely wrapped the Ni substrate, which meets the requirements as an ion-to-electron transducer in the electrode. In subsequent experiments and applications, the carbon film never peeled off from the nickel wire over a period of 5 months, confirming the excellent adhesion and stability of the carbon film prepared by this method. The traditional methods of carbon film coating preparation include chemical vapor deposition [26], plasma spraying [28] and multi-arc ion plating [29]. The bonding between the carbon coating and the substrate prepared by the above methods relies on organic bonding or Van der Waals forces, and the adhesion performance is poor. The cyclic voltammetry is simple, low cost and environmentally friendly [30]. Coating the surface of metallic materials using cyclic voltammetry increased the penetration process of the deposited carbon on the surface of the metal substrate as well as the adhesion between coating and substrate [24,30-33]. The carbon film prepared by electrochemical methods can effectively eliminate the interfacial impedance between the Ni substrate and the polymer film, solving the inherent problem of all-solid-state electrodes [24,25,34].

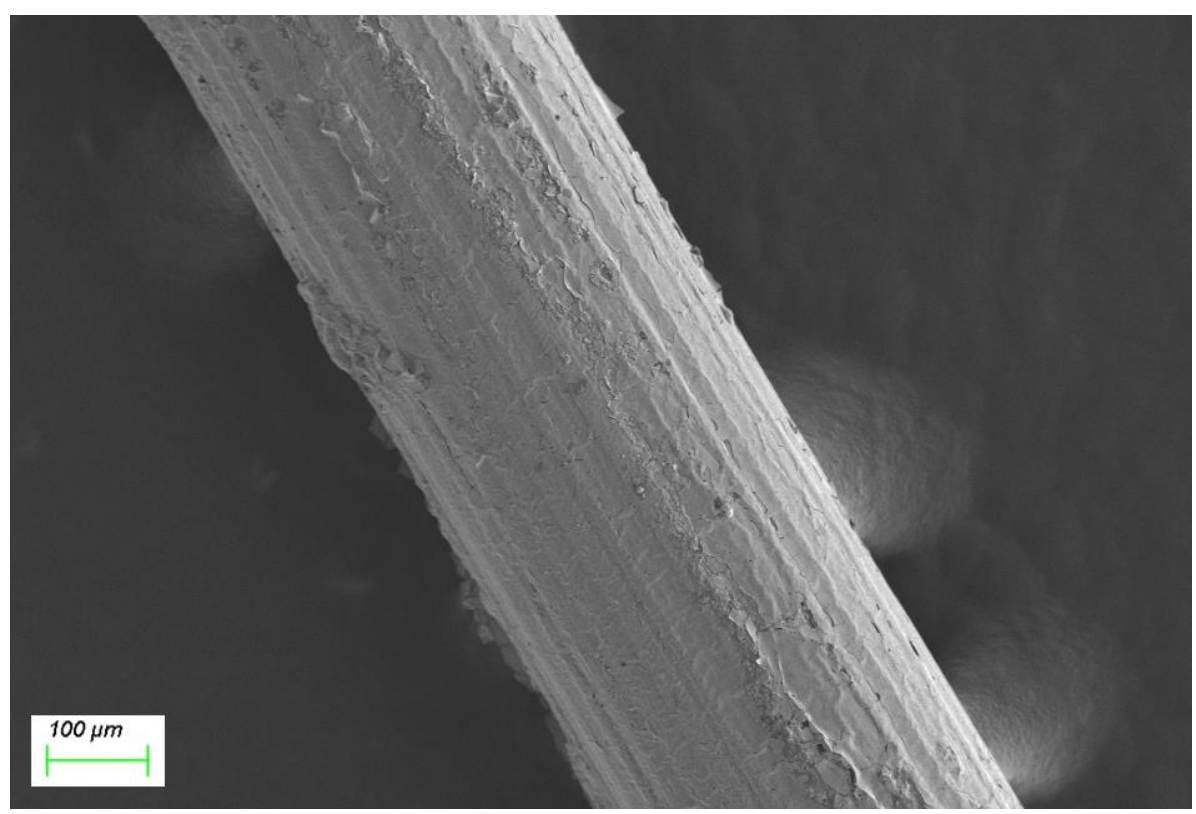

(a)

Figure 2. Cont. 


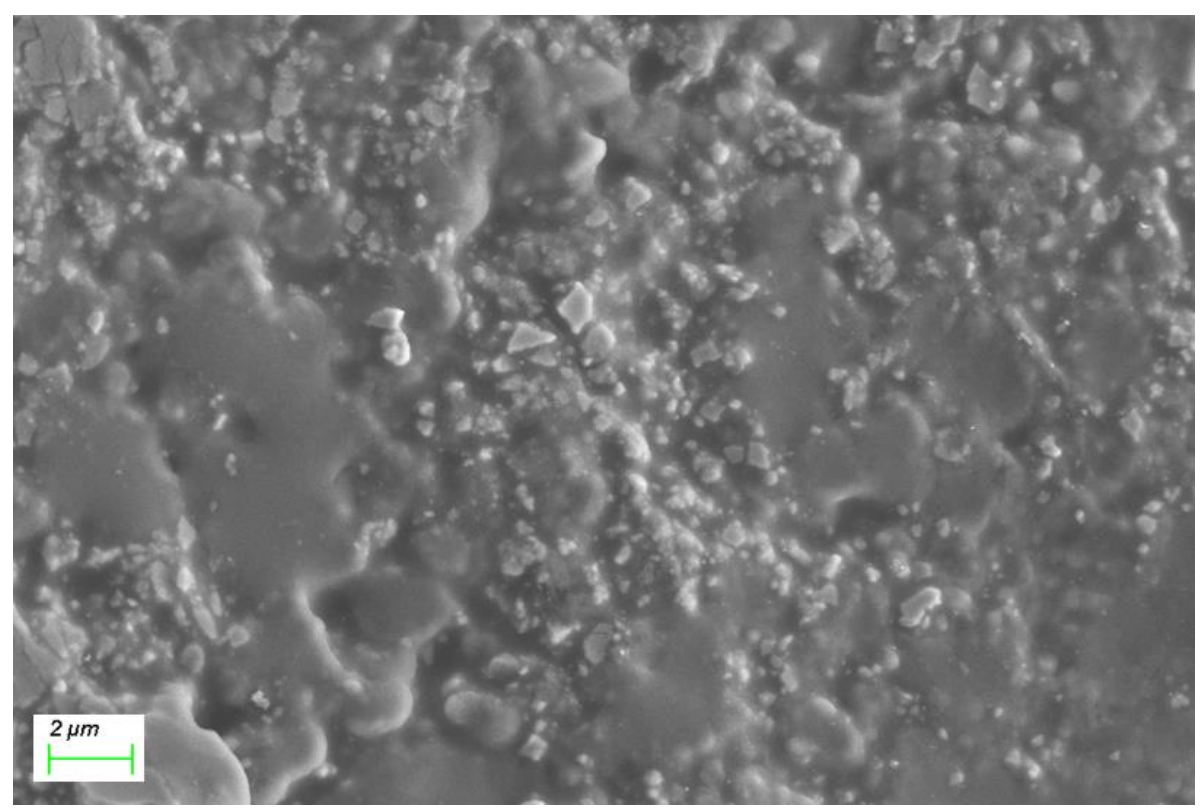

(b)

Figure 2. SEM images of the carbon film coating. (a) The Ni wire with carbon film coating viewed at $97 \times$ magnification, (b) the carbon film viewed at $4000 \times$ magnification.

The carbon film prepared by this method is a graphite carbon film, which has many excellent properties in addition to its application as an electrode substrate. The graphite carbon film effectively improves the lubricity, corrosion resistance and hardness of the metal substrate. In addition, metal-graphite coating has good resistance to high temperature molten salt corrosion, making it an ideal material for lithium-ion battery anodes $[25,35,36]$.

\subsection{Potentiometric Performance of the Electrode}

In this work, the carbonate ionophore VII (93206 Merck) with the chemical component bis (TFAB)CAs (N,N-dioctyl-7R-acetoxy-3R,12R-bis(4-trifluoroacetylbenzoxy)-5â-cholan24-amide) was used to prepare carbonate-sensitive films for ISE. The bis (TFAB)CAs recognize the incoming carbonate ion by forming both covalent and hydrogen bonding between the hydrated and unhydrated TFAB (trifluoroacetylbenzoxy) groups according to Merck [37]. The principle is the theoretical basis for the ability of this carbonate electrode to characteristically identify carbonate ions and determine $\mathrm{CO}_{3}{ }^{2-}$ concentrations. The voltage produced by the electrode is linearly related to the activity or concentration of the carbonate ion, in accordance with the Nernst equation [38]. In the following, the potential measurement properties of the electrodes were described by the slope of the calibration graph, the detection limit, selectivity factor, response time and life span.

\subsubsection{Linear Slope, Detection Limits and Calibration Curve}

The electrodes were activated in a $10^{-3} \mathrm{~mol} / \mathrm{L} \mathrm{Na}_{2} \mathrm{CO}_{3}$ solution for $3 \mathrm{~h}$ at room temperature before measurement. A range of $\mathrm{Na}_{2} \mathrm{CO}_{3}$ solutions at concentrations of $10^{-1} \mathrm{M}$, $10^{-2} \mathrm{M}, 10^{-3} \mathrm{M}, 10^{-4} \mathrm{M}, 10^{-5} \mathrm{M}, 10^{-6} \mathrm{M}, 10^{-7} \mathrm{M}, 10^{-8} \mathrm{M}$ were prepared for calibrating the ISE. The positive curve of the electrode obtained by plotting the electrode potential $E$ against the logarithm of the ion concentration in a given solution was shown in Figure 3. The detection limit was defined as the intersection of straight line and tangent part of the calibration curve. The linear range of the calibration curves was $10^{-1}-10^{-5} \mathrm{M}$ with detection limit was determined as $2.821 \times 10^{-6} \mathrm{M}$ and the line of fit of $\mathrm{y}=-30.40 \times-94.035$ $\left(\mathrm{R}^{2}=0.9996\right)$. The slope in the calibration curve was $-30.4 \mathrm{mV} /$ decade closing to the Nernst theoretical slope ( $-29.6 \mathrm{mV} /$ decade) [38]. In addition, the determination coefficient $\mathrm{R}^{2}$ was 0.9996 , indicating that the preparation method was reproducible. These data in- 
dicate that the carbonate electrode has a wide linear range $\left(10^{-5}\right.$ to $\left.10^{-1} \mathrm{M}\right)$ for $\mathrm{Na}_{2} \mathrm{CO}_{3}$ solutions and low detection limits.

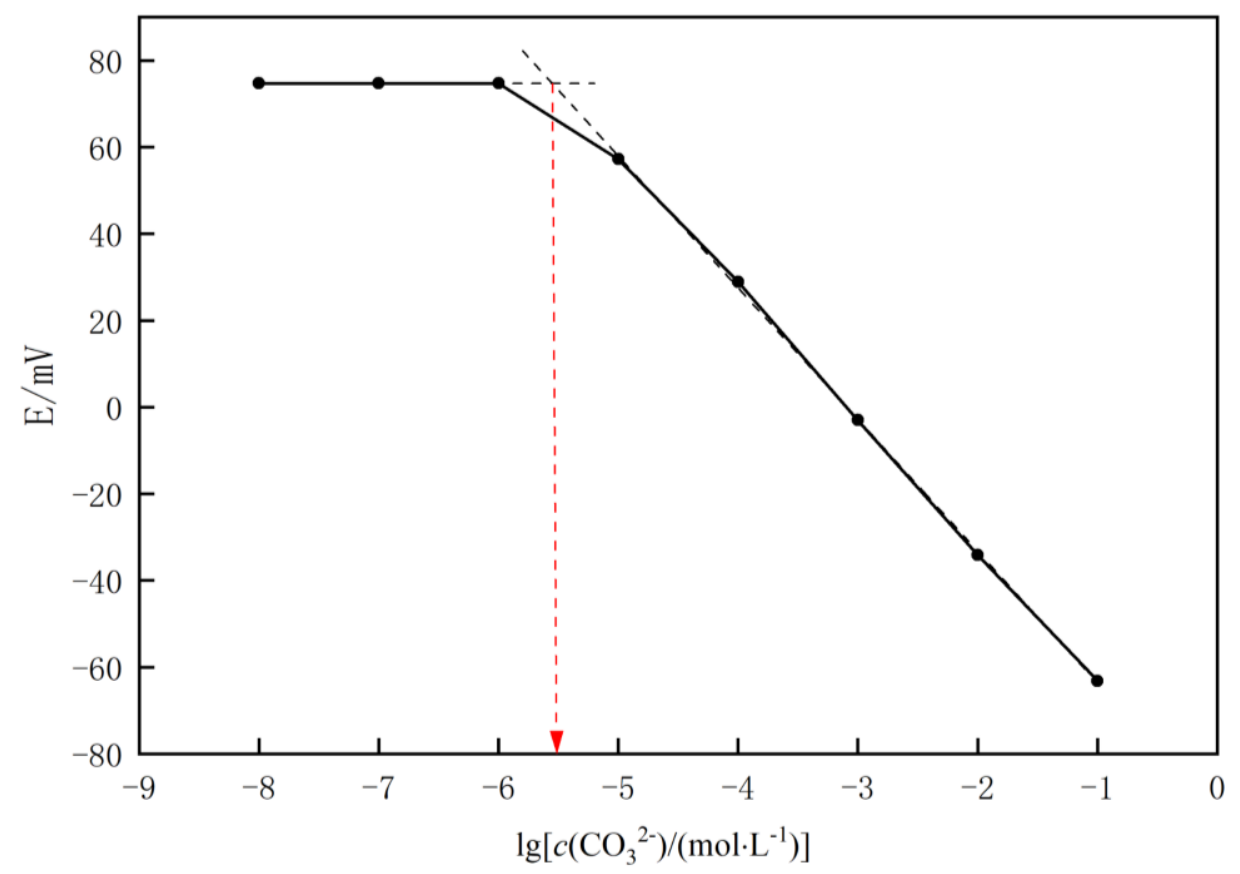

Figure 3. Electrode performance in $1 \times 10^{-8}-10^{-1} \mathrm{M} \mathrm{Na}_{2} \mathrm{CO}_{3}$ solution.

\subsubsection{Repeatability, Stability, Lifespan and Response Time}

Figure 4 shows the response curve of the carbonate ion-selective electrode in $\mathrm{Na}_{2} \mathrm{CO}_{3}$ solutions, with concentrations ranging from $10^{-5} \mathrm{M}$ to $10^{-1} \mathrm{M}$. The potentials were $57.23 \mathrm{mV}, 28.96 \mathrm{mV},-3.01 \mathrm{mV},-34.17 \mathrm{mV}$ and $-63.2 \mathrm{mV}$ from $10^{-5} \mathrm{M}$ to $10^{-1} \mathrm{M}$, then increased to $-34.21 \mathrm{mV},-3.06 \mathrm{mV}, 28.89 \mathrm{mV}$ and $57.31 \mathrm{mV}$ from $10^{-2} \mathrm{M}$ to $10^{-5} \mathrm{M}$. The potential curve showed that the carbonate electrode demonstrated a stable and consistent response to all concentrations of $\mathrm{Na}_{2} \mathrm{CO}_{3}$ in the test. Meanwhile, the potential difference in the concentration of the $\mathrm{Na}_{2} \mathrm{CO}_{3}$ solution, first from low to high, then from high to low, did not exceed $1 \mathrm{mv}$ at the same concentration, indicating the good repeatability of the carbonate ion-selective electrode.

In this work, the immersion method was used to determine the response time of this electrode, meaning the time it takes for the carbonate electrode to reach a stable value $(1 \mathrm{mV}$ from the steady state value) to the time of contact with the sample solution [39]. Figure 4 shows that once the electrodes were in contact with the solution, a constant potential signal is obtained within $1 \mathrm{~s}$ and remains constant during the measurement. The response time of less than $1 \mathrm{~s}$ means this electrode is practical when used for in situ measurements compared to the 60-120 s response time of other reported carbonate electrodes in recent years [19-22]. The rapid response of this carbonate electrode is related to its construction. As discussed in Section 3.1, there was the carbon layer as the transducer between carbonate-sensitive film and Ni wire. The dense carbon film, prepared by cyclic voltammetry, is tightly bonded to the nickel wire and polymer carbonate-sensitive film and its high conductivity also ensures the speed of electrical signal transmission. Due to this microstructure and its electrical conductivity, the cross-border resistance between the sensitive film coating, the carbon film and the metal wire is quite low and the electrical signal was conducted rapidly. 


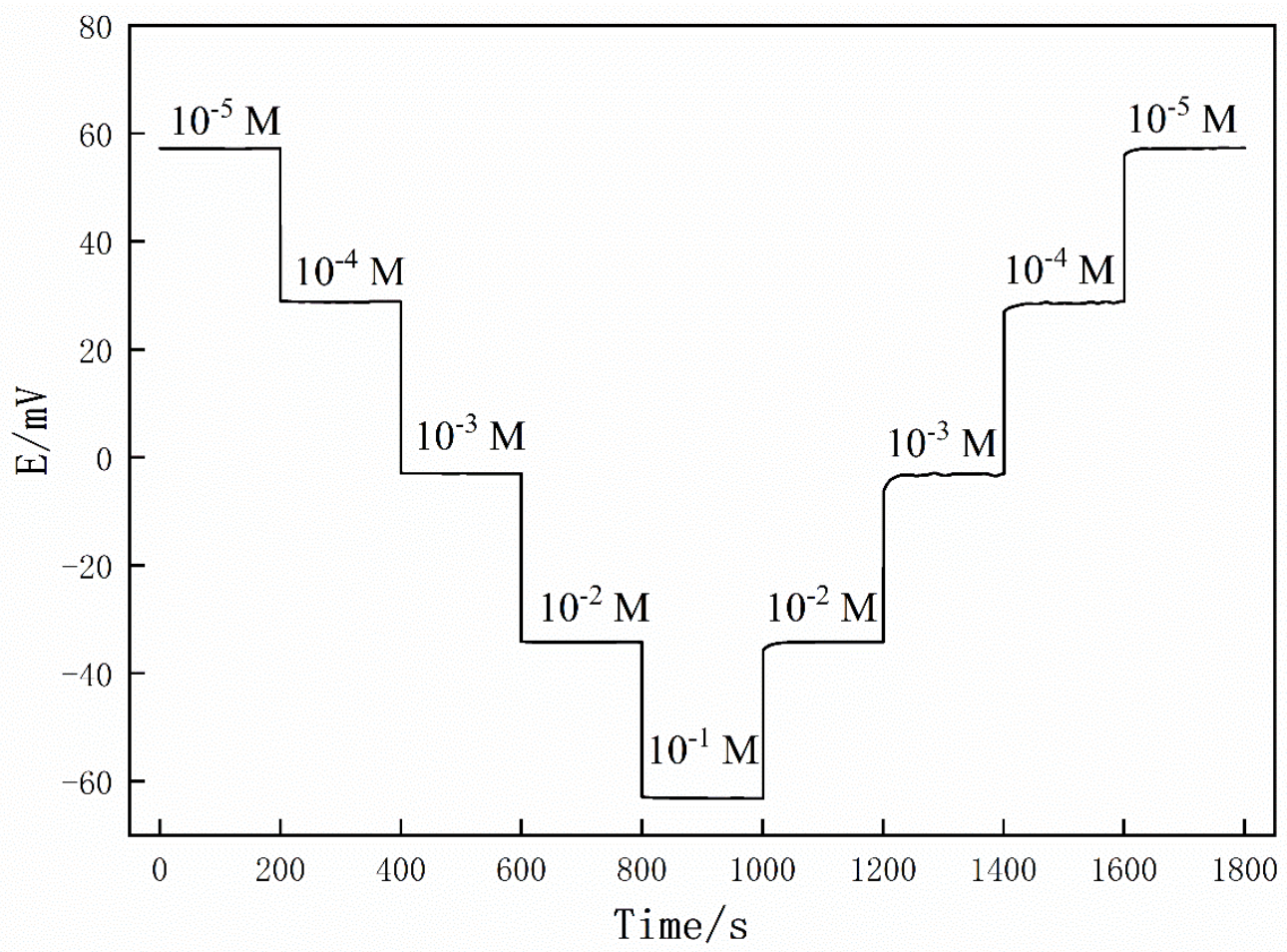

Figure 4. The calibration curve of the carbonate electrode for $\mathrm{Na}_{2} \mathrm{CO}_{3}$ solutions with concentrations ranging from $10^{-5} \mathrm{M}$ to $10^{-1} \mathrm{M}$.

To determine the life span of the electrode, the performance of the electrode was evaluated several times over a period of 60 days with a series of $\mathrm{Na}_{2} \mathrm{CO}_{3}$ solutions at room temperature [39]. The potential values of the electrodes, the slope and correlation coefficient of the calibration curve are displayed in Table 1 . The slope was stable between $-30 \pm 0.5 \mathrm{mV}$ over 60 days, with a determination coefficient $\mathrm{R}^{2}$ value greater than 0.98 . This indicates the electrode has a lifetime of more than 60 days and its lifetime meets the requirements for long-term monitoring of the marine environment.

Table 1. Performance of the ISE (mV) in the range of $10^{-5}-10^{-1} \mathrm{M} \mathrm{Na}_{2} \mathrm{CO}_{3}$ over 60 days.

\begin{tabular}{cccccccc}
\hline Day & $\mathbf{1 0}^{-\mathbf{5}} \mathbf{M}$ & $\mathbf{1 0}^{-\mathbf{4}} \mathbf{M}$ & $\mathbf{1 0}^{-\mathbf{3}} \mathbf{M}$ & $\mathbf{1 0}^{-\mathbf{2}} \mathbf{M}$ & $\mathbf{1 0}^{-\mathbf{1}} \mathbf{M}$ & Slope & $\mathbf{R}^{\mathbf{2}}$ \\
\hline 1 & 57.23 & 28.96 & -3.01 & -34.17 & -63.20 & -30.40 & $>0.99$ \\
3 & 56.68 & 29.04 & -2.96 & -33.86 & -62.03 & -30.03 & $>0.99$ \\
9 & 56.86 & 27.85 & -2.01 & -34.56 & -62.77 & -30.17 & $>0.99$ \\
17 & 55.45 & 26.11 & -0.12 & -36.93 & -65.54 & -30.50 & $>0.99$ \\
31 & 52.33 & 21.12 & -1.66 & -38.66 & -69.24 & -30.29 & $>0.99$ \\
43 & 55.39 & 19.34 & 1.26 & -39.23 & -63.21 & -29.58 & $>0.98$ \\
60 & 51.14 & 18.37 & 0.11 & -34.22 & -70.75 & -29.64 & $>0.98$ \\
\hline
\end{tabular}

\subsubsection{Selectivity}

The sensitive membrane of an ion-selective electrode has a specific response to the measured ion and the response of the electrode will be disturbed in the presence of other ions in solution [40]. The carbonate electrodes were intended to be applied to actual in situ measurements in the water containing a variety of interfering ions, compared with a pure $\mathrm{Na}_{2} \mathrm{CO}_{3}$ solution. Experiments on the selectivity of electrodes for some of the common interfering anions prevalent in the ocean are indispensable tests before application to the marine environment. The selection factor $\left(K_{i, j}\right)$ is calculated from the potential response of the electrode to the ion to be measured and the interfering ion. In this study, the selectivity coefficient of this carbonate electrode was calculated the fixed interference method (IFM). 
According to reports in the literature, the $\log K_{i, j}<0$ means the test electrode has good resistance to this interfering ion $j$ [41].

The response of the electrode to interfering ions was determined by mixing a fixed concentration of interfering ions in a series of $\mathrm{Na}_{2} \mathrm{CO}_{3}$ solutions of different concentrations $\left(10^{-1}-10^{-5} \mathrm{~mol} / \mathrm{L}\right)$. In this procedure, the following interferences were used: $\mathrm{SO}_{4}{ }^{2-}, \mathrm{Cl}^{-}$, $\mathrm{Br}^{-}, \mathrm{NO}_{2}^{-}, \mathrm{NO}_{3}^{-}, \mathrm{CH}_{3} \mathrm{COO}^{-}$and $\mathrm{OH}^{-}$with a fixed interfering ions concentration of $10^{-2} \mathrm{M}$. The results of the measurements are shown in Table 2. The constructed electrode showed little response to the major interfering ions present in seawater such as $\mathrm{Cl}^{-}, \mathrm{SO}_{4}{ }^{2-}$, $\mathrm{Br}^{-}$and $\mathrm{NO}_{3}{ }^{-}$(selectivity coefficients of $-4.24,-3.16,-2.21$ and -2.58 , respectively). Additionally, hydrolysis of carbonate ions may change the $\mathrm{pH}$ of the solution, the selection factor of $\mathrm{OH}^{-}<0(-3.44)$ indicating the electrode is responding to the carbonate rather than to the $\mathrm{OH}^{-}$from carbonate hydrolysis. The potential response of the prepared carbonate electrode was hardly affected by the $\mathrm{pH}$ of the solution. The findings showed that this carbonate electrode was highly resistant to seawater, had high selectivity for carbonate and can be used for resource exploration and environmental testing in the ocean.

Table 2. Selectivity factor measured for the carbonate electrode by the IFM.

\begin{tabular}{cccc}
\hline Interfering Ions & Slope & $\mathbf{R}^{\mathbf{2}}$ & $\log K_{i, j}$ \\
\hline $\mathrm{SO}_{4}{ }^{2-}$ & -30.62 & $>0.99$ & -3.16 \\
$\mathrm{Cl}^{-}$ & -30.99 & $>0.99$ & -4.24 \\
$\mathrm{Br}^{-}$ & -29.87 & $>0.99$ & -2.21 \\
$\mathrm{NO}_{2}{ }^{-}$ & -31.22 & $>0.98$ & -3.36 \\
$\mathrm{NO}_{3}{ }^{-}$ & -30.65 & $>0.99$ & -2.58 \\
$\mathrm{CH}_{3} \mathrm{COO}^{-}$ & -31.87 & $>0.98$ & -1.96 \\
$\mathrm{OH}^{-}$ & -29.94 & $>0.99$ & -3.44 \\
\hline
\end{tabular}

\subsection{Application at Southwest Indian Ocean Ridge}

The Southwest Indian Ridge (SWIR) extends from the Rodrigues Triple Junction (RTJ) in the east to the Bouvet Triple Junction (BTJ) in the west is the important boundary between the Antarctic and African plates [42]. Since the first confirmation of the high temperature active hydrothermal field 'Long qi' at the ultra-slow spreading oceanic ridge SWIR in 2007 [43], China Ocean Mineral Resources R\&D Association has carried out a series of sulphide exploration cruises at SWIR, discovering multiple hydrothermal fields [44-48].

Near-bottom detection of hydrothermal fields is currently the most widely used technique for seafloor hydrothermal activity investigations [10]. The development of in situ chemical sensors made it possible to monitor the spatial and instantaneous changes of hydrothermal fields $[49,50]$. The lack of oxygen supply to the deep-sea hydrothermal field and the anaerobic decomposition of the sulphide surface layer by bacteria produce large amounts of reducing components, resulting in a dramatic decrease in $\mathrm{pH}$ and $\mathrm{CO}_{3}{ }^{2-}$ concentration and an overall reductive water column [51-55]. The $\mathrm{pH}$, redox potential values and the carbonate concentration are important indicators for measuring and detecting hydrothermal field environment. However, carbonate sensors for deep-sea applications have not yet been reported. To remedy this deficiency, we integrated the carbonate electrode prepared in this paper with Eh (redox) and $\mathrm{pH}$ electrodes in a multi-parameter chemical sensor (MPCS) for hydrothermal field identification and detection at the SWIR where water depths of over $1400 \mathrm{~m}$. A schematic diagram of the internal structure of the MPCS is shown in Figure 5.

On 7 March 2021, MPCS was attached on the cable of the television camera grab (TVG) for underwater operations. The TVG was launched at 11:18 p.m. on 6 March 2021 and recovered at 02:50 a.m. on 7 March 2021. It was hauled by the research vessel Dayang Hao at a depth of 1400-1450 m during the Dayang 65 cruise. During the sulfide investigation, the near-bottom data obtained by the MPCS are of practical significance, thus we only presented the data between 00:29 and 01:36 a.m. in Figure 6. The MPCS was at a height of around $50 \mathrm{~m}$ above the seabed during operation. The potential anomaly at MPCS 
occurred at around 00:40 a.m. From 00:29 to 00:39 a.m., all three electrodes exhibited a smooth potential response. At 00:40 a.m., the three electrodes showed a synchronous sudden decrease in potential and returned to normal seawater background values within the next few minutes. The potential anomalies for the $\mathrm{Eh}, \mathrm{CO}_{3}{ }^{2-}$ and $\mathrm{pH}$ electrodes were $24 \mathrm{mV}$ (from $-44 \mathrm{mV}$ to $-68 \mathrm{mV}$ ), $30 \mathrm{mV}(-67 \mathrm{mV}$ to $-37 \mathrm{mV}$ ) and $32 \mathrm{mV}$ (from $136 \mathrm{mV}$ to $104 \mathrm{mV}$ ), respectively. The possibility of the sensor bottoming was ruled out after reviewing the board on site, the potential anomaly was predicted to be influenced by environmental changes of the water.

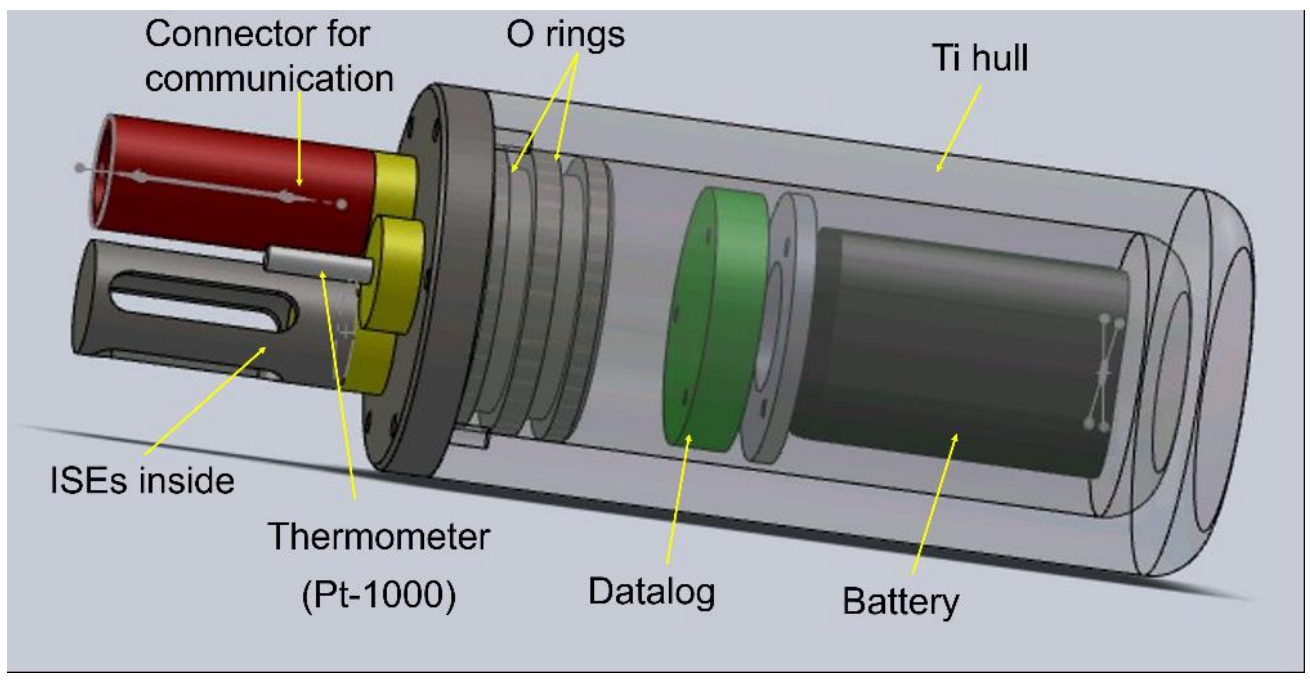

Figure 5. Assembly structure diagram of the MPCS.

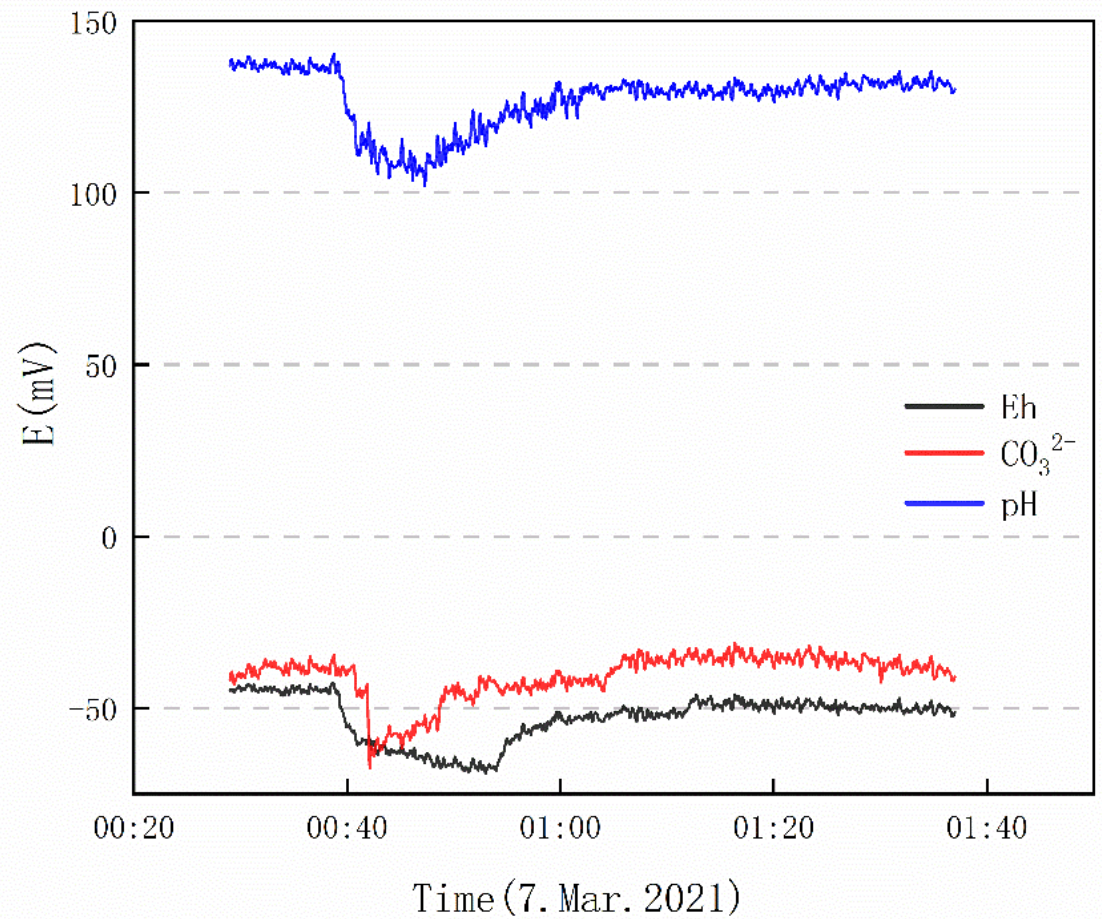

Figure 6. The $\mathrm{pH}, \mathrm{Eh}, \mathrm{CO}_{3}{ }^{2-}$ data obtained from the MPCS during the Dayang 65 cruise.

The $\mathrm{pH}$, Eh and $\mathrm{CO}_{3}{ }^{2-}$ electrodes showing a simultaneous decrease in potential meant the MPCS was in a strongly reducing water body with low $\mathrm{pH}$ value and high $\mathrm{CO}_{3}{ }^{2-}$ concentration. Figure 7 showed the screenshot from TVG video at 00:40 a.m. When potential anomalies occurred, the substrate type was an inactive sulphide accumulation, 
this area is a hydrothermal field. Potential anomalies detected by the MPCS were influenced by the particular environment of hydrothermal fields. With the movement of the TVG, the MPCS passed through the hydrothermal field, and returned to normal potential values at 01:10 a.m.

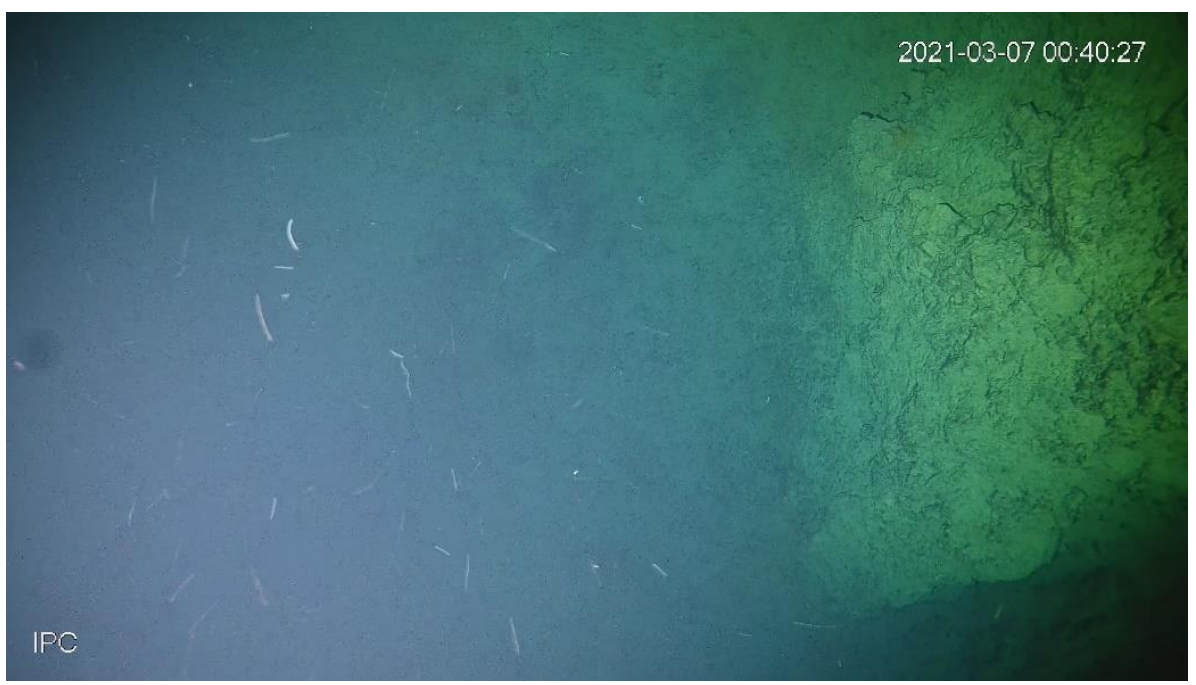

Figure 7. Screenshot of underwater the TVG camera video at 00:40 on 7 March 2021.

Then we grabbed a sulphide with the TVG at the hydrothermal field. Figure 8 showed its interior characteristic. The sample had a yellowish-brown surface with a dark grey fresh surface, massive structure, metallic lustrous pyrite grains visible to the naked eye. Hand specimen size: $15 \mathrm{~cm} \times 10 \mathrm{~cm} \times 7 \mathrm{~cm}$. The sulphide samples provided more information of the hydrothermal field. This carbonate electrode showed a corresponding potential anomaly in the defined hydrothermal field. The results demonstrated the carbonate electrode prepared in this paper is applicable to the search for hydrothermal activity in deep-sea environments, providing more abundant environmental information for sulphide exploration.

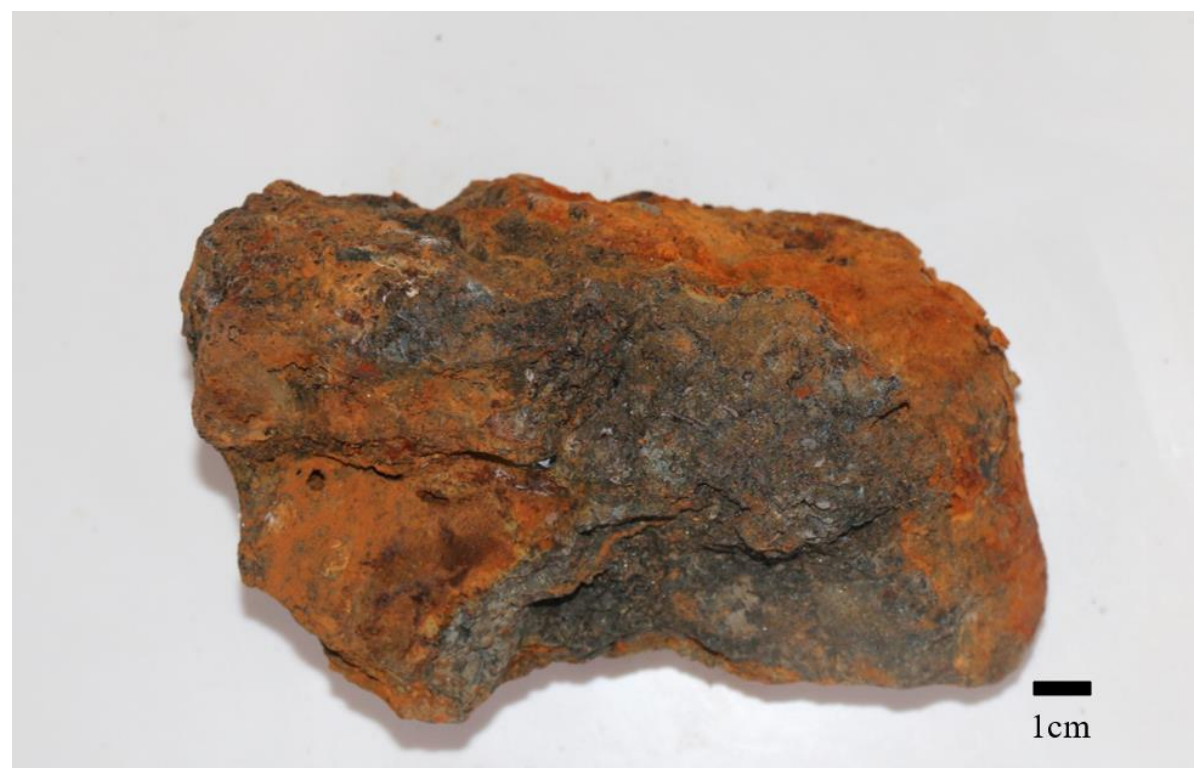

Figure 8. Interior photograph of the hydrothermal sulphide.

However, the deep-sea environment is characterised by low temperature, high salinity and high pressure, in situ $\mathrm{CO}_{3}{ }^{2-}$ concentrations cannot be obtained directly from the 
regular laboratory calibration curves. As a result, the detected potential signal cannot be converted into a quantitative concentration but the qualitative signals. Future work will focus on accurate measurement in the extreme environment to map the distribution of hydrothermal fields. Nonetheless, this carbonate electrode is already capable of preliminary hydrothermal activity detection and deep-sea resource exploration. An attempt will be made to integrate more functions into the sensor together with the carbonate electrode, in order to detect hydrothermal activity such as heat sensing, pressure sensing, acoustic sensing, photo sensing, etc. [56,57]

\section{Conclusions}

This work describes a novel all-solid-state carbonate ion-selective electrode with $\mathrm{Ni}$ wire as the base material and carbon film as the transducers and polymeric membrane as the carbonate-sensitive layer. The prepared ISE showed wide linear responses at an $\mathrm{Na}_{2} \mathrm{CO}_{3}$ concentration range of $10^{-5}-10^{-1} \mathrm{~mol} / \mathrm{L}$ with a response time of no more than $1 \mathrm{~s}$ and the detection limit of $2.821 \times 10^{-6} \mathrm{~mol} / \mathrm{L}$. The electrode response slope for $\mathrm{CO}_{3}{ }^{2-}$ was $-30.4 \mathrm{mV} /$ decade which was comparable to the theoretical Nernstian slope for divalent ions. It had good selectivity for $\mathrm{CO}_{3}{ }^{2-}$ and good resistance to the main interfering ions present in seawater, such as $\mathrm{Cl}^{-}, \mathrm{SO}_{4}{ }^{2-}, \mathrm{Br}^{-}$and $\mathrm{NO}_{3}{ }^{-}$. Meanwhile, the response of the ISE to carbonate ions barely affected by the $\mathrm{pH}$ of the solution. The prepared electrode, with a diameter of $0.5 \mathrm{~mm}$ and a length of 6-12 $\mathrm{mm}$, was easy to integrate with other electrodes. We integrated this carbonate electrode with $\mathrm{pH}$ electrode and Eh electrode in a multi-parameter chemical sensor. During the survey, the carbonic electrode showed the synchronous potential anomaly signal with the other electrodes in the hydrothermal field, providing enhanced information of the water column for hydrothermal field exploration. To our knowledge, this is the first report on the successful use of carbonate electrode for the detection of deep-sea hydrothermal activity. The application of this carbonate electrode in the field of marine environmental monitoring and its calibration curve in the extreme environment will be our future research direction.

Author Contributions: Conceptualization, C.Z.; methodology, C.Z., C.T. and Y.Y.; software, C.Z., C.T. and J.W.; validation, C.Z.; formal analysis, C.Z., P.Z. and Y.Y.; investigation, C.Z., Q.J., Y.H. and M.A.; resources, C.Z., Y.Y., C.T. and Y.H.; data curation, C.Z., J.W., W.C. and Q.J.; writing-original draft preparation, C.Z. and Y.H.; writing-review and editing, C.Z., Y.Y., C.T. and W.C.; visualization, C.Z.; supervision, C.T. and Y.Y.; project administration, C.T., Y.Y. and W.C.; funding acquisition, Y.Y., C.T. All authors have read and agreed to the published version of the manuscript.

Funding: This research was funded by the National Key R\&D Program of China (2018YFC0309900), National Natural Science Foundation of China (41276092), the Oceanic Interdisciplinary Program of Shanghai Jiao Tong University (SL2020MS031), Key R\&D of Zhejiang Province (2021C03183), Zhejiang provincial Natural Science Foundation of China (LY8D060005) and the Scientific Research Fund of Second Institute of Oceanography, MNR (SL2003).

Institutional Review Board Statement: Not applicable.

Informed Consent Statement: Not applicable.

Data Availability Statement: The data used to support the findings of this study are available from the corresponding author upon request.

Conflicts of Interest: The authors declare no conflict of interest.

\section{References}

1. Doney, S.C.; Ruckelshaus, M.; Duffy, J.E.; Barry, J.P.; Chan, F.; English, C.A.; Galindo, H.M.; Grebmeier, J.M.; Hollowed, A.B.; Knowlton, N.; et al. Climate Change Impacts on Marine Ecosystems. In Annual Review of Marine Science; Carlson, C.A., Giovannoni, S.J., Eds.; Annual Review of Marine Science; Annual Reviews: Palo Alto, CA, USA, 2012; Volume 4, pp. 11-37.

2. Zickfeld, K.; Azevedo, D.; Mathesius, S.; Matthews, H.D. Asymmetry in the climate-carbon cycle response to positive and negative CO2 emissions. Nat. Clim. Chang. 2021, 11, 613-617 . [CrossRef]

3. Dai, A.G.; Luo, D.H.; Song, M.R.; Liu, J.P. Arctic amplification is caused by sea-ice loss under increasing $\mathrm{CO}_{2}$. Nat. Commun. 2019, 10, 13. [CrossRef] [PubMed] 
4. Doney, S.C.; Fabry, V.J.; Feely, R.A.; Kleypas, J.A. Ocean Acidification: The Other $\mathrm{CO}_{2}$ Problem. Annu. Rev. Mar. Sci. 2009, 1, 169-192. [CrossRef]

5. Chen, S.; Tao, C.; Zhou, J.; Zhang, G.; Qin, H.; Wang, Y.; Chen, D. The distribution characteristics of hydrothermal plume in mid-ocean ridge and its indicative role in polymetallic sulfide prospecting. Acta Oceanol. Sin. 2019, 41, 1-12. [CrossRef]

6. Santana-Casiano, J.M.; Fraile-Nuez, E.; Gonzalez-Davila, M.; Baker, E.T.; Resing, J.A.; Walker, S.L. Significant discharge of CO 2 from hydrothermalism associated with the submarine volcano of El Hierro Island. Sci. Rep. 2016, 6, 25686. [CrossRef] [PubMed]

7. Beaulieu, S.E.; Baker, E.T.; German, C.R.; Maffei, A. An authoritative global database for active submarine hydrothermal vent fields. Geochem. Geophys. Geosyst. 2013, 14, 4892-4905. [CrossRef]

8. Blackford, J.; Bull, J.M.; Cevatoglu, M.; Connelly, D.; Hauton, C.; James, R.H.; Lichtschlag, A.; Stahl, H.; Widdicombe, S.; Wright, I.C. Marine baseline and monitoring strategies for carbon dioxide capture and storage (CCS). Int. J. Greenh. Gas Control 2015, 38, 221-229. [CrossRef]

9. Rubin, K.H.; Soule, S.A.; Chadwick, W.W.; Fornari, D.J.; Clague, D.A.; Embley, R.W.; Baker, E.T.; Perfit, M.R.; Caress, D.W.; Dziak, R.P. Volcanic Eruptions in the Deep Sea. Oceanography 2012, 25, 142-157. [CrossRef]

10. Baker, E.T.; Chadwick, W.W.; Cowen, J.P.; Dziak, R.P.; Rubin, K.H.; Fornari, D.J. Hydrothermal discharge during submarine eruptions the importance of detection, response, and new technology. Oceanography 2012, 25, 128-141. [CrossRef]

11. Ma, J.; Shu, H.L.; Yang, B.; Byrne, R.H.; Yuan, D.X. Spectrophotometric determination of $\mathrm{pH}$ and carbonate ion concentrations in seawater: Choices, constraints and consequences. Anal. Chim. Acta 2019, 1081, 18-31. [CrossRef]

12. Sharp, J.D.; Byrne, R.H.; Liu, X.W.; Feely, R.A.; Cuyler, E.E.; Wanninkhof, R.; Alin, S.R. Spectrophotometric Determination of Carbonate Ion Concentrations: Elimination of Instrument-Dependent Offsets and Calculation of In Situ Saturation States. Environ. Sci. Technol. 2017, 51, 9127-9136. [CrossRef]

13. Byrne, R.H.; Yao, W. Procedures for measurement of carbonate ion concentrations in seawater by direct spectrophotometric observations of $\mathrm{Pb}(\mathrm{II})$ complexation. Mar. Chem. 2008, 112, 128-135. [CrossRef]

14. Engleman, E.E.; Jackson, L.L.; Norton, D.R. Determination of carbonate carbon in geological-materials by coulometric titration. Chem. Geol. 1985, 53, 125-128. [CrossRef]

15. Weiss, R.F.; Craig, H. Precise shipboard determination of dissolved nitrogen, oxygen, argon, and total inorganic carbon by gas-chromatography. Deep Sea Res. 1973, 20, 291-303. [CrossRef]

16. Broecker, W.; Gerard, R.; Ewing, M.; Heezen, B.C. Natural radiocarbon in the atlantic ocean. J. Geophys. Res. 1960, 65, $2903-2931$. [CrossRef]

17. Goyet, C.; Snover, A.K. High-accuracy measurements of total dissolved inorganic carbon in the ocean-Comparison of alternate detection methods. Mar. Chem. 1993, 44, 235-242. [CrossRef]

18. An, Q.; Jia, F.; Xu, J.; Li, F.; Niu, L. Recent progress of all solid state ion selective electrode. Sci. Sin. Chim. 2017, 47, 524-531.

19. Zhao, Y.; Han, C.; Huang, Y.; Qin, W.; Zhang, X.; Kan, Y.; Ye, Y. New All-solid-state Carbonate Ion-selective Electrode with $\mathrm{Ag}_{2} \mathrm{CO}_{3}-\mathrm{BaCO}_{3}$ as Sensitive Films. Chem. Res. Chin. Univ. 2016, 32, 655-660. [CrossRef]

20. Mendecki, L.; Fayose, T.; Stockmal, K.A.; Wei, J.; Granados-Focil, S.; McGraw, C.M.; Radu, A. Robust and Ultrasensitive Polymer Membrane-Based Carbonate-Selective Electrodes. Anal. Chem. 2015, 87, 7515-7518. [CrossRef] [PubMed]

21. Mei, B.; Liang, R.; Qin, W. Solid-contact polymeric membrane potentiometric sensors for determination of carbonate in seawater samples. Chin. J. Anal. Lab. 2017, 36, 1255-1258.

22. Li, G.; Lyu, X.; Wang, Z.; Rong, Y.; Hu, R.; Luo, Z.; Wang, Y. All-solid-state carbonate-selective electrode based on screen-printed carbon paste electrode. Meas. Sci. Technol. 2017, 28, 025104. [CrossRef]

23. Yu, S.Y.; Li, F.H.; Yin, T.J.; Liu, Y.M.; Pan, D.W.; Qin, W. A solid-contact Pb2+-selective electrode using poly(2-methoxy-5-(2'ethylhexyloxy)-p-phenylene vinylene) as ion-to-electron transducer. Anal. Chim. Acta 2011, 702, 195-198. [CrossRef]

24. Boubiche, N.; El Hamouchi, J.; Hulik, J.; Abdesslam, M.; Speisser, C.; Djeffal, F.; Le Normand, F. Kinetics of graphitization of thin diamond-like carbon (DLC) films catalyzed by transition metal. Diam. Relat. Mat. 2019, 91, 190-198. [CrossRef]

25. Li, L.; Liu, A.; Xie, K.; Shi, Z. Preparation of Graphite Coating on Nickel Substrate by Molten Salt Electrolysis. J. Northeast. Univ. Nat. Sci. 2015, 36, 675-679.

26. Yudasaka, M.; Kikuchi, R.; Matsui, T.; Ohki, Y.; Ota, E.; Yoshimura, S. Graphite film formation by chemical vapor deposition on Ni coated sapphire. Carbon 1996, 34, 763-767. [CrossRef]

27. Wang, Z.; Wang, A.; Li, H.; Li, X.; Ke, P. Preparing Graphene Film Comprises Providing Substrate, Using Physical Vapor Deposition Method to Deposit Amorphous Carbon Film on Substrate and Depositing Nickel Film on Amorphous Carbon Film, and Annealing Amorphous Carbon and Nickel Film. Patent No CN109136842-A, 4 January 2019.

28. Cui, Y.; Li, G.; Jiang, L.; Wang, S. Drawing a Diamond Coating on a Drawing Die Comprises e.g. Using DC Arc Plasma Jet Method to Depositing Diamond Coating on the Inner Hole of the Drawing Die, Placing Drawing Die to Be Processed into a Mold Bushing Assembly. Patent No CN110042361-A, 23 July 2019.

29. Song, Q.S.; Xu, Q.; Xing, C.Y. Preparation of a gradient Ti-TiOC-carbon film by electro-deposition. Electrochem. Commun. 2012, 17, 6-9. [CrossRef]

30. Prasai, D.; Tuberquia, J.C.; Harl, R.R.; Jennings, G.K.; Bolotin, K.I. Graphene: Corrosion-Inhibiting Coating. ACS Nano 2012, 6, 1102-1108. [CrossRef] [PubMed] 
31. Hameed, R.M.A.; Mohamed, I.M.A.; Al-Enizi, A.M.; Abutaleb, A.; Shaikh, S.F.; Yousef, A. Fabrication of electrospun nickel sulphide nanoparticles onto carbon nanofibers for efficient urea electro-oxidation in alkaline medium. Int. J. Hydrogen Energy 2021, 46, 12944-12960. [CrossRef]

32. Filipe, O.M.S.; Brett, C.M.A. Characterization of carbon film electrodes for electroanalysis by electrochemical impedance. Electroanalysis 2004, 16, 994-1001. [CrossRef]

33. Massot, L.; Chamelot, P.; Bouyer, F.; Taxil, P. Electrodeposition of carbon films from molten alkaline fluoride media. Electrochim. Acta 2002, 47, 1949-1957. [CrossRef]

34. Hwang, S.H.; Iwamoto, R.; Okumura, T.; Kamataki, K.; Itagaki, N.; Koga, K.; Nakatani, T.; Shiratani, M. Comparison between $\mathrm{Ar}+\mathrm{CH} 4$ cathode and anode coupling chemical vapor depositions of hydrogenated amorphous carbon films. Thin Solid Film. 2021, 729, 7. [CrossRef]

35. Cai, B.; Tan, Y.F.; Tu, Y.Q.; Wang, X.L.; Xu, T. Effects of graphite content on microstructure and tribological properties of graphite/TiC/Ni-base alloy composite coatings. Trans. Nonferrous Met. Soc. China 2011, 21, 1741-1749. [CrossRef]

36. Chen, X.H.; Chen, C.S.; Xiao, H.N.; Cheng, F.Q.; Zhan, G.; Yi, G.J. Corrosion behavior of carbon nanotubes-Ni composite coating. Surf. Coat. Technol. 2005, 191, 351-356. [CrossRef]

37. Choi, Y.S.; Lvova, L.; Shin, J.H.; Oh, S.H.; Lee, C.S.; Kim, B.H.; Cha, G.S.; Nam, H. Determination of oceanic carbon dioxide using a carbonate-selective electrode. Anal. Chem. 2002, 74, 2435-2440. [CrossRef] [PubMed]

38. Brumleve, T.R.; Buck, R.P. Numerical-solution of nernst-planck and poisson equation system with applications to membrane electrochemistry and solid-state physics. J. Electroanal. Chem. 1978, 90,1-31. [CrossRef]

39. Wu, J.B.; Zhou, Y.F.; Zhang, P.P.; Zhang, C.Q.; Ye, Y. An All-Solid-State Phosphate Ion-Selective Electrode Using BiPO 4 as a Sensitive Membrane. Int. J. Electrochem. Sci. 2021, 16, 12. [CrossRef]

40. Eren, H.; Uzun, H.; Andac, M.; Bilir, S. Potentiometric monitoring of cobalt in beer sample by solid contact ion selective electrode. J. Food Drug Anal. 2014, 22, 413-417. [CrossRef]

41. Wu, R.R.; Chen, X.G.; Tao, C.H.; Huang, Y.F.; Ye, Y.; Wang, Q.J.; Zhou, Y.F.; Jin, Q.; Cai, W. An All-Solid-State Silicate Ion-Selective Electrode Using PbSiO3 as a Sensitive Membrane. Sensors 2019, 19, 525. [CrossRef]

42. Tao, C.H.; Li, H.M.; Huang, W.; Han, X.Q.; Wu, G.H.; Su, X.; Zhou, N.; Lin, J.; He, Y.H.; Zhou, J.P. Mineralogical and geochemical features of sulfide chimneys from the $49 \mathrm{~A}$ degrees $39^{\prime}$ E hydrothermal field on the Southwest Indian Ridge and their geological inferences. Chin. Sci. Bull. 2011, 56, 2828-2838. [CrossRef]

43. Tao, C.H.; Lin, J.; Guo, S.Q.; Chen, Y.J.; Wu, G.H.; Han, X.Q.; German, C.R.; Yoerger, D.R.; Zhou, N.; Li, H.M.; et al. First active hydrothermal vents on an ultraslow-spreading center: Southwest Indian Ridge. Geology 2012, 40, 47-50. [CrossRef]

44. Zhang, Y.X.; Liao, S.L.; Tao, C.H.; Wen, H.J.; Fan, H.F.; Wen, J.; Yang, W.F.; Li, W. Ga isotopic fractionation in sulfides from the Yuhuang and Duanqiao hydrothermal fields on the Southwest Indian Ridge. Geosci. Front. 2021, 12, 9. [CrossRef]

45. Liao, S.L.; Zhu, C.W.; Zhou, J.P.; Liu, W.Y.; Yu, J.Y.; Liang, J.; Yang, W.F.; Li, W.; Liu, J.; Tao, C.H. Distal axis sulfide mineralization on the ultraslow-spreading Southwest Indian Ridge: An LA-ICP-MS study of pyrite from the East Longjing-2 hydrothermal field Acta Oceanol. Sin. 2021, 40, 105-113. [CrossRef]

46. Zhou, Y.D.; Zhang, D.S.; Zhang, R.Y.; Liu, Z.S.; Tao, C.H.; Lu, B.; Sun, D.; Xu, P.; Liu, R.C.; Wang, J.J.; et al. Characterization of vent fauna at three hydrothermal vent fields on the Southwest Indian Ridge: Implications for biogeography and interannual dynamics on ultraslow-spreading ridges. Deep Sea Res. Part I Oceanogr. Res. Pap. 2018, 137, 1-12. [CrossRef]

47. Liao, S.L.; Tao, C.H.; Li, H.M.; Barriga, F.; Liang, J.; Yang, W.F.; Yu, J.Y.; Zhu, C.W. Bulk geochemistry, sulfur isotope characteristics of the Yuhuang-1 hydrothermal field on the ultraslow-spreading Southwest Indian Ridge. Ore Geol. Rev. 2018, 96, 13-27. [CrossRef]

48. Tao, C.H.; Li, H.M.; Jin, X.B.; Zhou, J.P.; Wu, T.; He, Y.H.; Deng, X.M.; Gu, C.H.; Zhang, G.Y.; Liu, W.Y. Seafloor hydrothermal activity and polymetallic sulfide exploration on the southwest Indian ridge. Chin. Sci. Bull. 2014, 59, 2266-2276. [CrossRef]

49. Wu, R.R.; Tao, C.H.; Chen, X.G.; Ye, Y.; Yue, X.H.; Huang, Y.Q.; Zhou, Y.F.; Wang, Q.Q. Fabrication of Multi-parameter Chemical Sensor and its Application in the Longqi Hydrothermal Field, Southwest Indian Ocean. Int. J. Electrochem. Sci. 2019, 14, 3871-3884. [CrossRef]

50. Ding, Q.; Pan, Y.W.; Huang, Y.F.; Chen, C.T.A.; Ye, Y. The optimization of Ag/Ag2S electrode using carrier electroplating of nano silver particles and its preliminary application to offshore Kueishan Tao, Taiwan. Cont. Shelf Res. 2015, 111, 262-267. [CrossRef]

51. Baumberger, T.; Lilley, M.D.; Lupton, J.E.; Baker, E.T.; Resing, J.A.; Buck, N.J.; Walker, S.L.; Fruh-Green, G.L. Dissolved Gas and Metal Composition of Hydrothermal Plumes From a 2008 Submarine Eruption on the Northeast Lau Spreading Center. Front. Mar. Sci. 2020, 7, 15. [CrossRef]

52. German, C.R.; Baker, E.T.; Mevel, C.; Tamaki, K.; Team, F.S. Hydrothermal activity along the southwest Indian ridge. Nature 1998, 395, 490-493. [CrossRef]

53. Baker, E.T.; Massoth, G.J. Characteristics of hydrothermal plumes from 2 vent fields on the juan-de-fuca ridge, northeast pacific-ocean. Earth Planet. Sci. Lett. 1987, 85, 59-73. [CrossRef]

54. Shitashima, K. $\mathrm{CO}_{2}$ supply from deep-sea hydrothermal systems. Waste Manage. 1997, 17, 385-390. [CrossRef]

55. Sakai, H.; Gamo, T.; Kim, E.S.; Tsutsumi, M.; Tanaka, T.; Ishibashi, J.; Wakita, H.; Yamano, M.; Oomori, T. Venting of carbon-dioxide rich fluid and hydrate formation in mid-okinawa trough backarc basin. Science 1990, 248, 1093-1096. [CrossRef] [PubMed]

56. Yan, W.; Qu, Y.P.; Das Gupta, T.; Darga, A.; Nguyen, D.T.; Page, A.G.; Rossi, M.; Ceriotti, M.; Sorin, F. Semiconducting Nanowire-Based Optoelectronic Fibers. Adv. Mater. 2017, 29, 1700681. [CrossRef] [PubMed]

57. Abouraddy, A.F.; Bayindir, M.; Benoit, G.; Hart, S.D.; Kuriki, K.; Orf, N.; Shapira, O.; Sorin, F.; Temelkuran, B.; Fink, Y. Towards multimaterial multifunctional fibres that see, hear, sense and communicate. Nat. Mater. 2007, 6, 336-347. [CrossRef] [PubMed] 